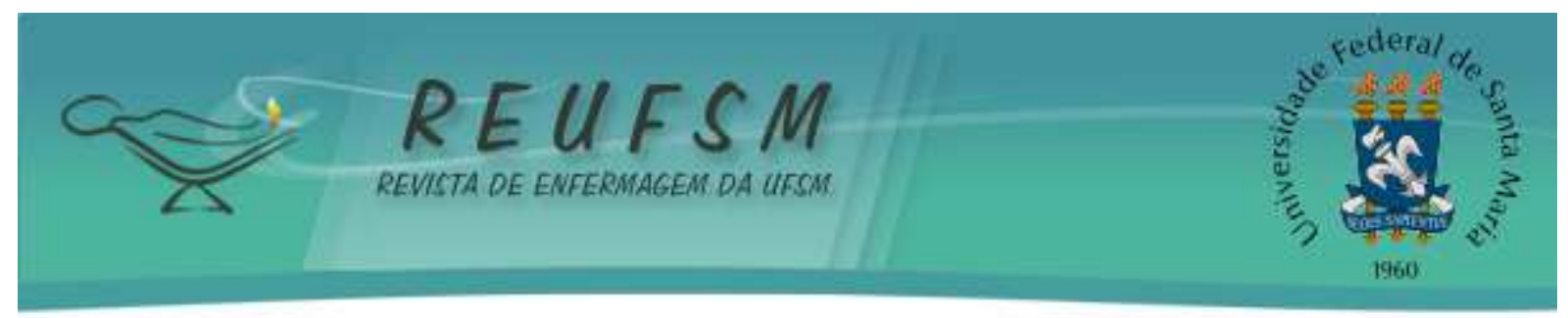

\title{
CONHECIMENTO DE ACADÊMICOS ACERCA DA PREVENÇÃO DO CÂNCER DE COLO DO ÚTERO E DE MAMA
}

\author{
KNOWLEDGE OF ACADEMICS ABOUT CERVICAL AND BREAST CANCER \\ PREVENTION
}

\section{CONOCIMIENTO DE ACADÉMICOS SOBRE LA PREVENCIÓN DEL CÁNCER DE CUELLO UTERINO Y DE MAMA}

\author{
Janaína Pereira Jales Rocha ${ }^{1}$ \\ Kalyane Kelly Duarte de Oliveira ${ }^{2}$ \\ Leonardo Magela Lopes Matoso ${ }^{3}$ \\ Sibele Lima da Costa Dantas ${ }^{4}$ \\ Clécio André Alves da Silva Maia ${ }^{5}$
}

Doi: $10.5902 / 2179769227839$

RESUMO: Objetivo: analisar o conhecimento de acadêmicos acerca da prevenção do câncer de colo do útero e de mama. Método: estudo quantitativo, descritivo, realizado em uma universidade privada. Os participantes foram acadêmicos dos cursos de Enfermagem, Fisioterapia e Nutrição do $2^{\circ}$ ao $8^{\circ}$ período. Analisou-se os dados por meio de estatística descritiva. Resultados: evidenciou-se que os acadêmicos têm um bom conhecimento sobre a prevenção do câncer de colo do útero e de mama. Mas $61 \%$ referem limitações para orientar as pessoas, visto que 59\% das disciplinas não contribuem para tal. Conclusão: evidencia-se a importância da formação voltada para realidade da população, de forma que os futuros profissionais da saúde desenvolvam com competência as ações propostas pelas políticas de saúde, entre elas a política de controle do câncer de mama e colo do útero.

Descritores: Neoplasias da mama; Neoplasias do colo do útero; Promoção da saúde

ABSTRACT: Aim: to analyze the knowledge of academics about the prevention of cervical and breast cancer. Method: quantitative, descriptive study, conducted at a private university. The subjects were academics of Nursing, Physiotherapy and Nutrition courses from the 2nd to the 8th period. Data were analyzed through descriptive statistics. Results: it has been shown that academics have a good knowledge about the prevention of cervical and breast cancer. But $61 \%$ of the participants mention limitations in guiding people, since 59\% of the academic subjects do not contribute to it. Conclusion: the importance of training focused on the reality of the population is evidenced, so that future health professionals can competently develop the actions proposed by health policies, for instance, the policy of control of breast and cervical cancer, among others.

Descriptors: Breast neoplasms; Uterine cervical neoplasms; Health promotion

\footnotetext{
${ }^{1}$ Enfermeira. Especialista em Urgência e Emergência. Prefeitura Municipal de Mossoró. Mossoró, Rio Grande do Norte, Brasil. E-mail: janainajales@ hotmail.com

${ }^{2}$ Enfermeira. Doutora em Enfermagem. Universidade do Estado do Rio Grande do Norte. Mossoró, Rio Grande do Norte, Brasil. E-mail: kenfoliveira@gmail.com

${ }^{3}$ Enfermeiro. Mestre em Cognição, Tecnologias e Instituições. Universidade Federal Rural do Semiárido. Mossoró, Rio Grande do Norte, Brasil. E-mail: leonardo.l.matoso@gmail.com

${ }^{4}$ Enfermeira. Mestre em Cuidados Clínicos em Saúde. Universidade Estadual do Ceará. Mossoró, Rio Grande do Norte, Brasil. E-mail: sibelelcosta@gmail.com

${ }^{5}$ Enfermeira. Mestre em Planejamento e Dinâmicas Territoriais no Semiárido. Universidade do Estado do Rio Grande do Norte. Mossoró, Rio Grande do Norte, Brasil. E-mail: clecioandre@ gmail.com
} 


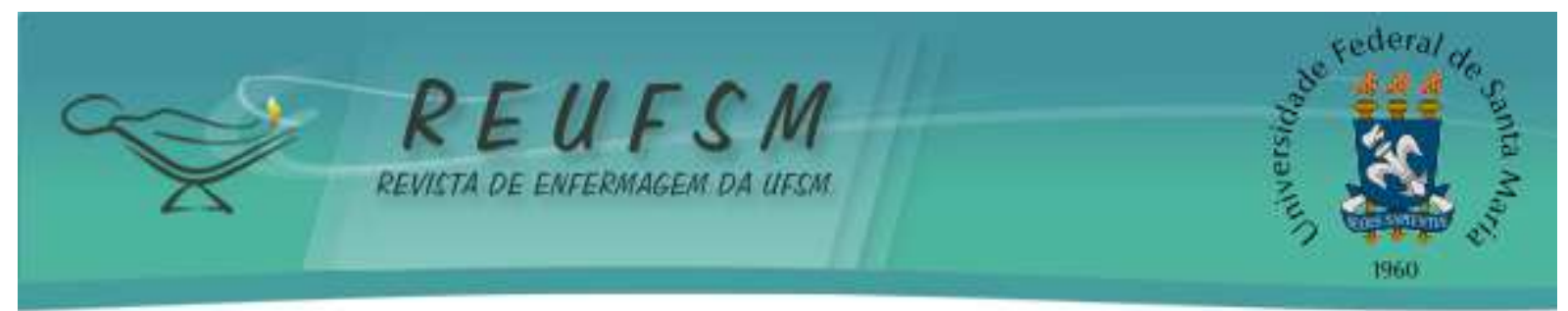

RESUMEN: Objetivo: analizar el conocimiento de los académicos sobre la prevención del cáncer de cuello uterino y del cáncer de mama. Método: estudio cuantitativo, descriptivo, realizado en una universidad privada. Los participantes de la investigación fueron los estudiantes de los cursos de Enfermería, Fisioterapia y Nutrición del $2^{o}$ al $8^{o}$ período. Los datos fueron analizados por medio de estadística descriptiva. Resultados: se evidenció que los académicos tienen un buen conocimiento sobre la prevención del cáncer de cuello de útero y de mama. Pero, $61 \%$ relatan limitaciones para orientar a las personas, ya que 59\% de las asignaturas no contribuyen para ello. Conclusión: se identificó la importancia de la formación centrada en la realidad de la población, de forma que los futuros profesionales de salud desarrollen efectivamente las acciones propuestas por las politicas de salud, entre esas la política de control del cáncer de mama y del cuello de útero.

Descriptores: Neoplasias de la mama; Neoplasias del cuello uterino; Promoción de la salud

\section{INTRODUÇÃO}

Os atuais modelos de vida seguidos em relação ao trabalho, nutrição e consumo em geral expõem os indivíduos a fatores ambientais mais agressivos, relacionados a agentes químicos, físicos e biológicos resultantes de um processo de industrialização cada vez mais evoluído. Em relação à população feminina, os tipos de câncer mais comuns são os de mama, colo do útero e colo retal. O alto índice de óbitos por câncer levou o Ministério da Saúde a organizar ações nacionais voltadas para a prevenção e o controle desses cânceres em todos os níveis de atenção. ${ }^{1}$

As ações relacionadas ao controle dependem do nível de informação e conhecimento da população assistida tendo em vista que é o ponto inicial para o planejamento da assistência do profissional da saúde, de acordo com os princípios de integralidade e humanização. ${ }^{2}$ Entre as medidas de controle cita-se o autocuidado que é reconhecido como uma habilidade humana, sendo que sua execução está diretamente ligada às condições que cada indivíduo possui para cuidar de si. $^{2}$

As medidas de autocuidado para prevenção do câncer de colo do útero e mama estão relacionadas aos fatores modificáveis individuais, como exemplo, menciona-se: a interrupção do uso do tabaco; práticas sexuais seguras com o uso do preservativo evitando-se a disseminação do Papiloma Vírus Humano (HPV); realização regular dos exames Papanicolau, mamografia e autoexame das mamas. ${ }^{3}$

Compreender o nível de conhecimento de estudantes universitários acerca da prevenção para o câncer de mama e colo do útero em uma perspectiva inter e pluridisciplinar, é importante para repensar a inserção da educação em saúde como conteúdo curricular imprescindível para melhorar a capacitação dos acadêmicos e futuros profissionais no 


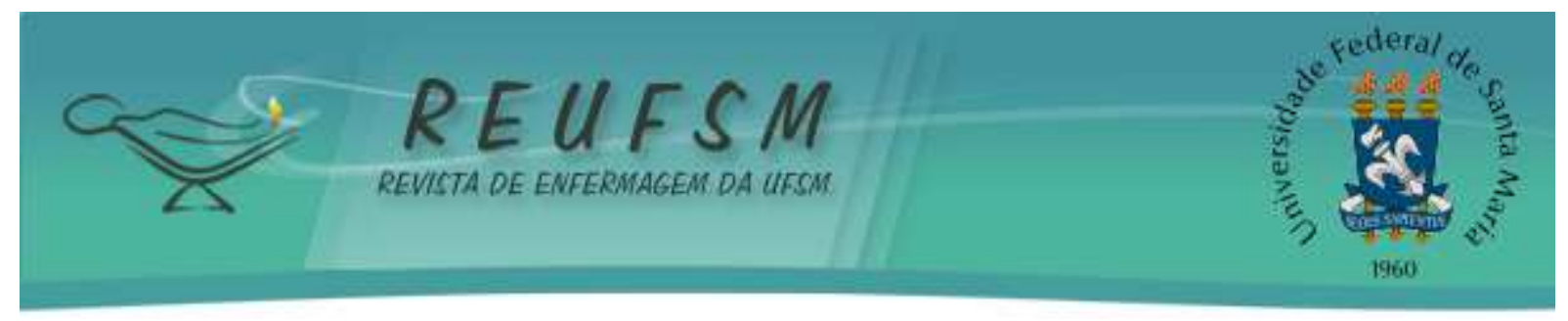

desenvolvimento de estratégias de promoção à saúde. Por outro lado, sendo o câncer de mama e colo do útero, agravos crônicos e não transmissíveis, a educação, tendo em vista a sua prevenção e detecção precoce, não deve se constituir na simples transmissão de informação, mas ter por base o contexto sociocultural, valores, crenças e conhecimento popular. ${ }^{2}$

Nesse contexto, o conhecimento para a prevenção do câncer de colo do útero e de mama é fundamental, cabendo à instituição de ensino superior o papel indispensável na formação, criação e divulgação destes conhecimentos, também de realizar estratégias de prevenção e promoção da saúde.

Diante do contexto, questionou-se: qual o conhecimento dos acadêmicos em relação à prevenção do câncer de colo do útero e de mama? Assim, o estudo objetivou analisar o conhecimento de acadêmicos acerca da prevenção do câncer de colo do útero e de mama.

\section{MÉTODO}

Estudo quantitativo, de natureza descritiva, desenvolvido na Universidade Potiguar Campus Mossoró/Rio Grande do Norte (RN), Brasil, que comporta na escola da saúde, os cursos de Enfermagem, Fisioterapia e Nutrição. Os participantes da pesquisa foram os alunos matriculados nos cursos de Enfermagem, Fisioterapia e Nutrição do $2^{\circ}$ ao $8^{\circ}$ período, somando um total de 296 entrevistados, dos turnos matutino e noturno dos períodos citados, sendo eles: 131 alunos de enfermagem, 110 alunos de nutrição e 55 alunos do curso de fisioterapia.

Utilizou-se como critério de inclusão: acadêmicos do $2^{\circ}$ ao $8^{\circ}$ período dos cursos de enfermagem, nutrição e fisioterapia. Foram excluídos os que estavam de atestado médico ou licença maternidade. Não foram incluídos neste estudo os alunos do $1^{\circ}$ período, por se tratar de iniciantes e dessa forma não tiveram disciplinas sobre a temática da pesquisa. Também não participaram os estudantes do $9^{\circ}$ e $10^{\circ}$ períodos, por estarem a maior parte do tempo nos serviços de saúde, em estágios supervisionados, dificultando o encontro com os mesmos para realização da pesquisa.

Coletaram-se os dados entre os meses de outubro e dezembro de 2015 na universidade, utilizando um questionário estruturado aplicado pela pesquisadora. Os participantes foram convidados na hora do intervalo, combinando data, horário e sala. Os participantes foram aleatórios e, antes de aceitarem participar da pesquisa, foram informados sobre os objetivos, metodologia, riscos e benefícios envolvidos. 


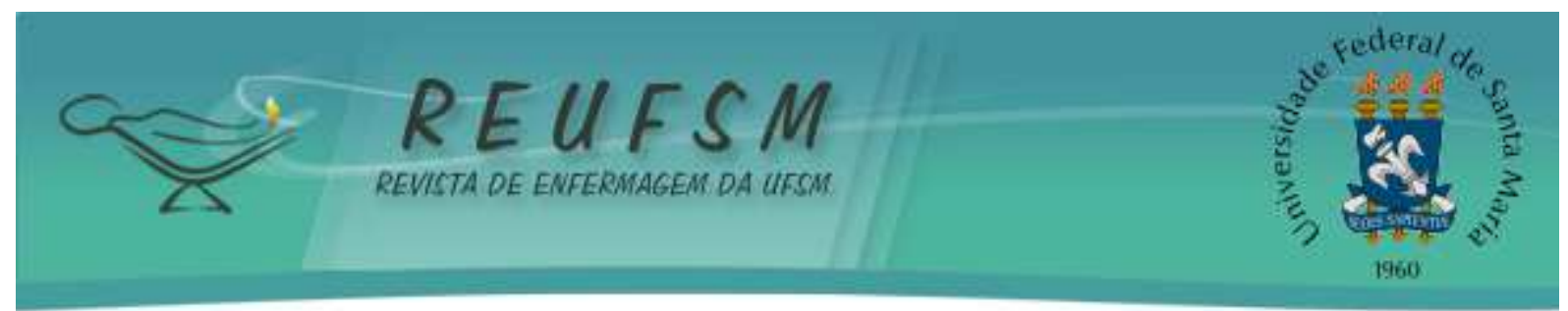

Nesta pesquisa foram respeitados os aspectos éticos segundo a Resolução n. 466/12, Conselho Nacional de Saúde (CNS). O trabalho foi aprovado pelo Comitê de Ética em Pesquisa da Universidade Potiguar (CEP/UnP), sob o Parecer $n^{\circ} 834.979$ e CAAE: 35048714.3.0000.5296, na data de 28 de outubro de 2014.

Assegurou-se, aos entrevistados, a confidencialidade e a privacidade de sua identidade ao solicitar o preenchimento do Termo de Consentimento Livre e Esclarecido (TCLE), caso aceitasse participar da pesquisa. Em seguida, os participantes responderam a um questionário estruturado contendo perguntas de múltipla escolha, podendo responder mais de uma das alternativas e seguidas de alternativas diretas.

Para análise dos dados recorreu-se à organização no Microsoft Excel e apresentação por meio da estatística descritiva. Deste modo, realizou-se uma discussão de acordo com a literatura.

\section{RESULTADOS E DISCUSSÃO}

Iniciou-se a coleta de dados investigando o conhecimento dos acadêmicos acerca da incidência do câncer de útero e mama e os hábitos de vida que colaboram para o surgimento dos casos.

Questionou-se aos acadêmicos se tinham conhecimento sobre o câncer de colo do útero e de mama. Dentre os 296 entrevistados, 47\% relatou ter conhecimento acerca do câncer de mama e colo do útero, distinguindo sinais característicos, fatores de risco e formas de diagnóstico precoce, $50 \%$ afirmou ter pouco conhecimento e 2,3\% disse não ter nenhum conhecimento sobre o assunto.

O conhecimento acerca do câncer de útero e mama, incluindo os sinais e sintomas, formas de prevenção, diagnóstico e tratamentos destacam-se como importantes na prática profissional, pois os acadêmicos irão se deparar com seus clientes nos serviços de saúde é para que tal prática se efetive, é necessária uma formação profissional pautada no atendimento integral e resolutivo. ${ }^{4}$

Assim, $100 \%$ dos acadêmicos relataram que a população mais afetada pelo câncer de mama é a população feminina, sendo que $46 \%$ não sabiam que o câncer de mama pode incidir, também, na população masculina.

O câncer de mama em homens é doença de acontecimento raro, sendo estimado cerca de um caso a cada 100 mil habitantes na maioria dos locais. ${ }^{1}$ Apesar dos dados apontarem que a população feminina é mais afetada pelo câncer de mama, deve-se enfatizar medidas de 


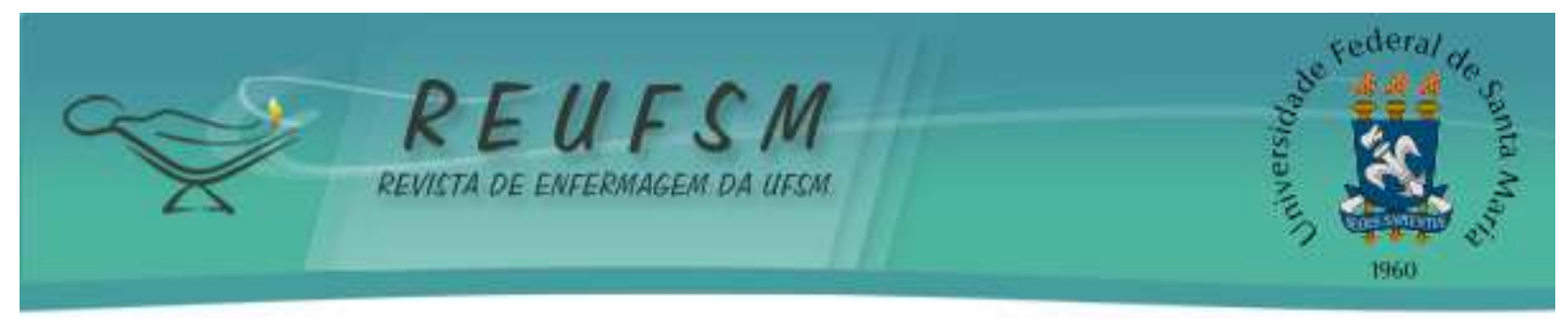

prevenção e controle para o câncer de mama na população masculina, uma vez que nessa população, quando descoberto o tumor, este já se encontra em estágios mais avançados, dificultando um bom prognóstico e a possível cura.

Os acadêmicos salientaram alguns hábitos de vida que podem contribuir para o surgimento do câncer de mama e colo do útero, destacando-se dois hábitos: 65\% autocuidado ineficaz, 59\% alimentação inadequada, 49\% sedentarismo, 44\% tabagismo, 17\% etilismo, e apenas 4,7\% afirmaram que nenhum destes hábitos contribuem para o aparecimento do câncer de mama e colo de útero.

Uma alimentação desprovida de fibras, com altos teores de gordura e calorias leva a um maior risco para o desenvolvimento de câncer colorretal, de mama e de próstata. A alta proporção de gordura aumenta a quantidade de estrógenos. Este hormônio é considerado essencial para o organismo, entretanto, em níveis altos aumenta o risco do surgimento do câncer de mama. Quando as mulheres têm uma alimentação com baixo teor de gorduras, seus níveis de estrógeno diminuem expressivamente em pouco tempo. Evitar laticínios também pode reduzir os riscos de câncer de mama. ${ }^{5}$

O risco de câncer de mama aumenta em pessoas obesas porque a gordura é estrogênica. Os estrógenos que são transformados em estrona, por meio da androstenediona também podem ser transformados em estradiol no próprio tecido adiposo por atividade. $\mathrm{O}$ tecido adiposo é um grande depósito de esteroides, uma vez que a reação enzimática responsável pela conversão de andrógenos a estrógenos acontece tanto em homens quanto nas mulheres, assim sendo a obesidade é um fator de risco. ${ }^{5-6}$ Por isso a importância da alimentação adequada e a prática regular de atividade física.

Estudos defendem que a atividade física regular tem um papel protetor em relação ao câncer em alguns locais, principalmente, aqueles relacionados aos hormônios femininos, como o da mama e do endométrio. ${ }^{6-7}$

O álcool está relacionado ao aumento do risco de vários tipos de câncer: boca, faringe, laringe, esôfago, fígado, mama e intestino, e este risco aumenta independentemente do tipo de bebida. $^{7}$ A associação do câncer com a bebida alcoólica é considerado, destacando-se que quanto mais se bebe maior o risco de ter este. ${ }^{8}$

Cita-se que o tabaco e o álcool são fatores de risco preponderantes, não só para o desenvolvimento da neoplasia assim como para seu prognóstico. Em meio às mulheres, o 


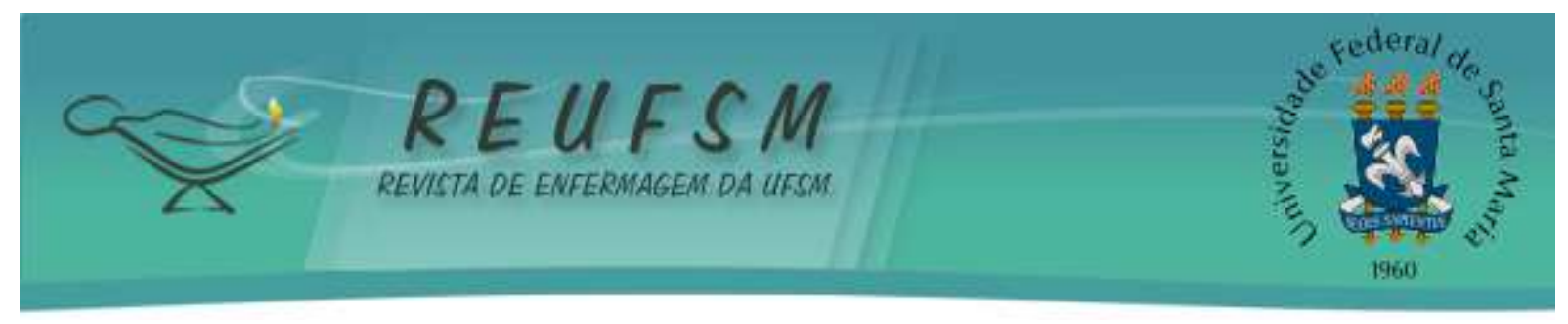

risco de câncer de mama pode ser $60 \%$ maior entre as que consomem 15 gramas ou mais de etanol em comparação as que não consomem bebidas alcoólicas. ${ }^{8}$

O hábito de fumar, por si só, já é causa suficiente para o episódio de câncer no indivíduo, porém, na presença de outros fatores prejudiciais à saúde, pode haver a potencialização do risco de desenvolvimento de neoplasias. Pode-se considerar como fatores associados à ocorrência de câncer o tabagismo, o sedentarismo, o consumo frequente de álcool e o sobrepeso. ${ }^{8-9}$

Diante do exposto, $94 \%$ dos acadêmicos responderam que as medidas de autocuidado ajudam no controle do câncer de mama e colo do útero, $5 \%$ relataram que ajudam pouco, e $1 \%$ afirmou que não ajuda.

Estima-se que cerca de $30 \%$ de todas as neoplasias podem ser e que a partir das práticas de autocuidado, é possível modificar o risco de desenvolvimento do câncer. As modificações são influenciadas por orientações grupais, a construção de manuais educativos, orientações sobre como prevenir o câncer por meio da realização de exames de diagnóstico precoce como o Papanicolau e a educação sexual como aliados na detecção de células précancerigenas. As modificações dependem, portanto, de mudanças no estilo de vida individual, do desenvolvimento de ações e regulamentações governamentais, de alterações culturais na sociedade e dos resultados de novas pesquisas. ${ }^{3}$

É necessário, então, que os profissionais da saúde conheçam e detectem os fatores de risco modificáveis para o câncer, a fim de implementar ações que visem sua modificação. ${ }^{10}$ Menciona-se, ainda, a importância dos acadêmicos da saúde não só adquiram o conhecimento para incentivar o paciente sobre o autocuidado, como também identifiquem o valor o cuidado de si na prevenção e controle do câncer de mama e colo de útero, uma vez que a mudança no estilo de vida ajuda nessa prevenção.

Sobre as medidas de autocuidado para prevenção do câncer de colo do útero e da mama, os acadêmicos citaram medidas gerais e específicas. Em relação às primeiras, 49\% apontaram a prática regular de atividade física, 39\% citaram o mapeamento genético, 32\% responderam o controle do tabagismo, $29 \%$ manutenção de peso corporal, $27 \%$ o consumo moderado ou ausente de álcool entre outros fatores menos mencionados.

Alguns estudos também levantam a hipótese de que a atividade física pode modificar a expressão de receptores de estrógeno e de progesterona (ER/PR). Mulheres mais ativas tendem a ter maior quantidade de globulinas que se ligam a receptores hormonais, menor 


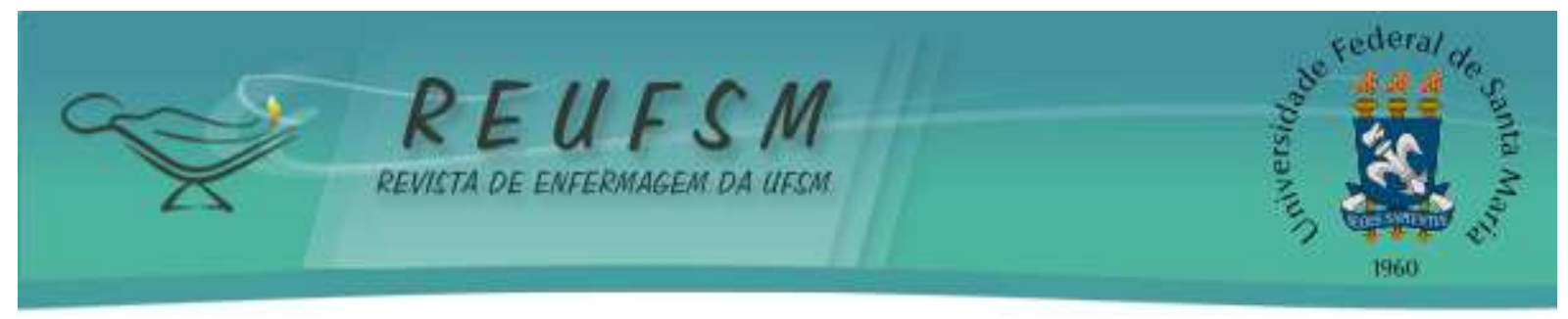

concentração sérica de estrógeno, e, logo, menor expressão de ER/PR, uma vez que esses genes são ativados em parte pelo estrogênio. ${ }^{6}$

Quanto ao mapeamento genético, esse pode comprovar diagnósticos, identificar pessoas sadias portadoras de um gene patogênico e, ainda, fornecer várias informações présintomáticas, inclusive sobre os riscos de adoecimento futuro e morte precoce. $\mathrm{O}$ conhecimento genético utilizado com segurança, pode constituir um novo marco para a promoção da saúde e a prevenção do adoecimento, inclusive por câncer. ${ }^{11}$

Sobre o álcool, embora existam controvérsias, têm muitas evidências de que este pode aumentar o risco de câncer de útero e mama por meio de diversos mecanismos, condicionado ou não de hormônios. O etanol pode atuar como carcinogênico, aumentando a permeabilidade da membrana celular a carcinógenos, inibindo a detoxificação dos mesmos pelo fígado, prejudicando o metabolismo de nutrientes e induzindo ao estresse oxidativo. Além disso, pode atuar como mutagênico por meio do acetaldeído, e pode aumentar os níveis séricos de estrógenos e a atividade de transcrição do receptor de estrógeno, elevando a resposta da célula à ação deste hormônio. ${ }^{12}$

Em relação às medidas de autocuidado para proteção e detecção precoce do câncer de mama, $85 \%$ citaram o autoexame das mamas e $73 \%$ apontaram a realização da mamografia.

O câncer de mama, na pluralidade das vezes, possui um bom prognóstico quando diagnosticado e tratado a tempo, entretanto as taxas de mortalidade continuam altas no Brasil, possivelmente pelo fato de a doença ser diagnosticada em estágios avançados. ${ }^{13} \mathrm{O}$ diagnóstico precoce da doença está ligado, diretamente, ao acesso à informação, a conscientização das pessoas sobre a realização do autoexame da mama, do exame clínico e do exame de mamografia, tríade na qual deve se basear o rastreamento dessa neoplasia. ${ }^{3}$

Conforme dados coletados acerca das medidas de autocuidado para prevenção do câncer de mama, verificou-se que a mamografia foi a mais citada, uma vez que pode ser considerada uma medida de despertar nas mulheres para se autocuidar.

A inspeção cuidadosa das mamas é parte importante do atendimento integral à saúde da mulher e deve ser executada nos diferentes níveis de atenção à saúde. Esse é o essencial foco do rastreamento oportunístico em especial para as mulheres jovens, em idade fértil, independente da identificação de fatores de risco. ${ }^{12-13}$

Ainda que recentemente seja de utilidade discutível por sua baixa relação com a redução da mortalidade por câncer de mama, o autoexame apresenta vantagens especialmente 


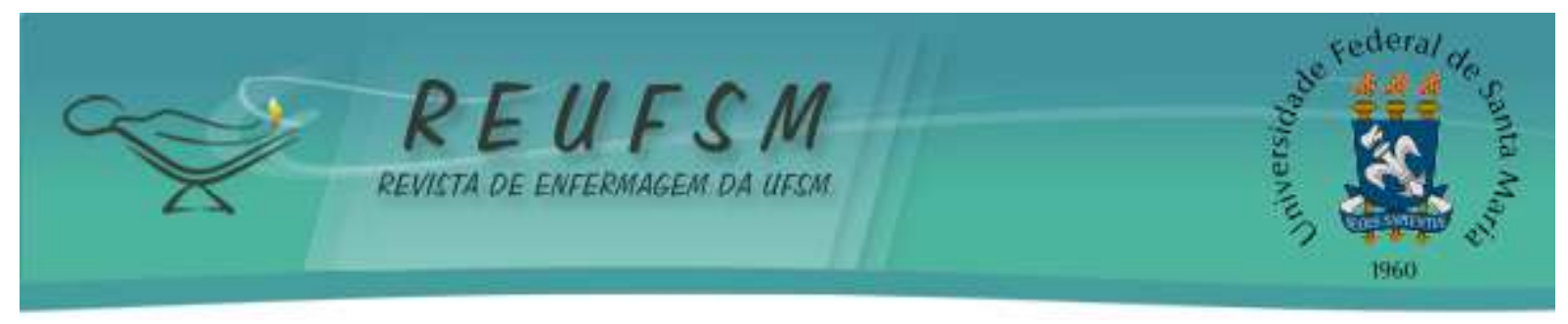

no contexto do autocuidado da saúde das mamas e na redução de casos avançados em regiões carentes dos métodos de imagem. ${ }^{13}$

Já em relação as medidas de autocuidado para prevenção do câncer do colo do útero, $70 \%$ apontam a realização periódica do exame Papanicolau e 58\% citam a importância de usar preservativos nas relações sexuais para evitar o HPV.

O início precoce da vida sexual (antes dos 18 anos), ter muitos parceiros e a falta de higiene estão relacionados a um maior risco de câncer do colo uterino. De tal modo, os hábitos sexuais contribuem para a propagação de agentes sexualmente transmissíveis que podem induzir ao câncer, como o herpes vírus II e o HPV, que estão relacionados com o câncer do colo uterino. ${ }^{2}$

O HPV está presente em 94\% dos casos de câncer do colo de útero, que é o terceiro câncer que mais mata no Brasil, mesmo sendo uma doença que pode ser detectada por meio do exame citopatológico. Algumas mulheres desenvolvem a doença e não procuram um serviço de saúde, por vezes, pela carência de informação sobre o assunto, ou pela dificuldade de acesso para realizar o exame periodicamente, pois em acompanhamento frequente fica mais fácil a descoberta precoce e tratamento para uma possível cura. ${ }^{2}$

Garantir uma cobertura de rastreamento mínima de $80 \%$ a $85 \%$ da população feminina de 25-59 anos, prezar pela qualidade de realização do exame citopatológico e garantir tratamento oportuno e seguimento das pacientes, são algumas das recomendações da Organização Mundial de Saúde para impactar o perfil epidemiológico do câncer do colo do útero. ${ }^{14}$

A realização periódica do exame citopatológico continua sendo a estratégia mais adotada para o rastreamento do câncer do colo do útero. Alcançar alta cobertura da população definida como alvo é o componente importante no âmbito da atenção primária para que se obtenha significativa redução da incidência e da mortalidade por câncer do colo do útero. ${ }^{14}$

Ao realizar esse exame anualmente a mulher está cuidando de si e conhecendo seu corpo, ajudando na descoberta e tratamento precoce de infecções por vírus, como o HPV, uma vez que está relacionado com o desenvolvimento do câncer de colo do útero. Ressalta-se, portanto, a prática sexual com o uso do preservativo e boa higiene íntima, para diminuir a incidência da doença e desenvolvimento do câncer de colo do útero. Profissionais orientados para tais procedimentos colaboram para orientação do usuário para seu autocuidado.

Questionou-se aos acadêmicos sobre as disciplinas que dão ênfase ao câncer de colo do útero e câncer de mama, e sobre a prevenção, 59\% relataram que somente algumas 


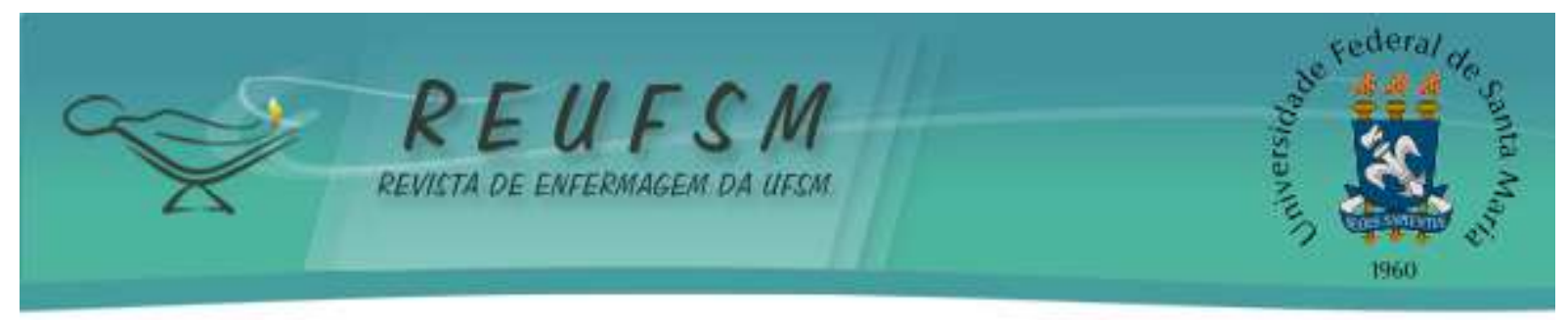

disciplinas na grade curricular abordam tais temas, e $41 \%$ relataram não ter visto nenhuma disciplina que fale sobre o assunto.

Evidencia-se a importância de uma melhor abordagem do assunto nas universidades para que os alunos possam desenvolver habilidades e competências de educadores em saúde para o exercício da profissão. Conhecer e examinar o corpo é indispensável no processo prevenção de doenças e estabelecimento de autocuidado e deve fazer parte da rotina diária. Em seu cotidiano, o enfermeiro e os demais profissionais da área da saúde vêm, a cada dia, empenhando-se mais para a consolidação de ações educativas que promovam a saúde e o bem-estar da população. ${ }^{15}$

Quando questionados sobre estarem preparados para orientar a população acerca das medidas para prevenção e detecção precoce, $61 \%$ responderam negativamente. Essa constatação reforça a importância da formação acadêmica voltada para realidade da população, para que os futuros profissionais da saúde possam desenvolver, com competência, as ações propostas pelas políticas públicas de controle ao câncer de mama e colo do útero.

Assim, o conhecimento das práticas de autocuidado contribui para a realização de um processo de educação em saúde que possibilite incentivar os estilos de vida saudáveis, desestimular os hábitos inadequados, contemplando as necessidades de cada indivíduo. ${ }^{3}$

\section{CONCLUSÃO}

Evidenciou-se que os acadêmicos de enfermagem, fisioterapia e nutrição tem um bom conhecimento sobre o assunto, embora afirmem não estar preparados para orientar a população. Visto a importância das medidas de prevenção para o controle dos cânceres de colo do útero e de mama, enfatiza-se a necessidade de os acadêmicos estudarem o assunto ainda na universidade, para que os futuros profissionais saiam do âmbito acadêmico com conhecimentos, tanto para seu autocuidado como preparados para orientar e cuidar do outro.

O estudo salientou a importância da articulação entre sistema de saúde, gestão e dos processos de formação. Tal articulação colocaria em evidência a formação em saúde como construção da educação em serviço, de forma a conhecer e trabalhar mais próximo às necessidades de saúde em cada território de atuação, agregando o desenvolvimento individual do aluno à melhoria dos serviços de atenção à saúde e o controle social.

Dessa forma, compreender o nível de conhecimento de acadêmicos sobre a prevenção do câncer de mama e colo do útero em uma perspectiva multiprofissional, é importante para 


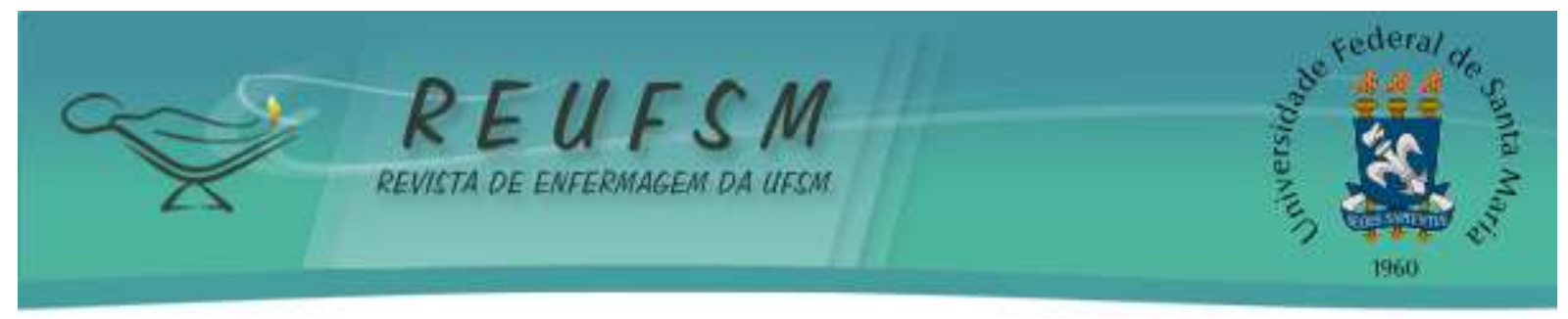

rever a inclusão da educação em saúde como conteúdo curricular indispensável, uma vez que a instituição de ensino superior tem o seu papel de formação, criação de conhecimentos e divulgação destes, e ainda de realizar estratégias de prevenção e promoção da saúde. Dessa forma, enfatiza-se a necessidade de continuar as pesquisas sobre a temática, com vistas a direcionar ações efetivas de orientação, de prevenção para o câncer de colo do útero e de mama entre os universitários, futuros profissionais de saúde.

\section{REFERÊNCIAS}

1. Instituto Nacional do Câncer José Alencar Gomes da Silva (INCA). Coordenação Geral de Ações Estratégicas. Coordenação de Prevenção e Vigilância. Estimativa 2014: incidência de câncer no Brasil. Rio de Janeiro: INCA; 2014.

2. Rodrigues AB, Oliveira PP. Oncologia para enfermagem. Rio de Janeiro: Editora Manole; 2016.

3. Souza MGG, Santos I, Silva LA. Educação em saúde e ações de autocuidado como determinantes para prevenção e controle do câncer. Rev Pesqui Cuid Fundam [Internet]. 2015 out [acesso em 2018 jul 19];7(4):3274-91. Disponível em: http://dx.doi.org/10.9789/21755361.2015.v7i4.3274-3291.

4. Pereira CT, Moreira LA. A interface do enfermeiro educador na detecção precoce do câncer de mama: reflexão à enfermagem. Rev UNIABEU [Internet]. 2012 maio-ago [acesso em 2014 out 20];5(10):127-42. Disponível em: http://revista.uniabeu.edu.br/index.php/RU/article/view/397/pdf_205.

5. Munhoz MP, Oliveira J, Gonçalves RD, Zambon TB, Oliveira LCN. Efeito do exercício físico e da nutrição na prevenção do câncer. Rev Odontol Araçatuba [Internet]. 2016 maioago [acesso em 2017 abr 12];37(2):9-16. Disponível em: http://apcdaracatuba.com.br/revista/2016/08/trabalho5.pdf.

6. Figueiredo ACDS, Ferreira RNF, Duarte MAG, Coelho AF, Cabral KMAA. Prevalência da obesidade em mulheres tratadas de câncer de mama numa UNACOM em Juiz de Fora. Rev Bras Mastologia [Internet]. 2016 [acesso em 2017 abr 11];26(4):169-74. Disponível em: http://www.rbmastologia.com.br/wp-content/uploads/2016/11/MAS-v26n4_169-174.pdf.

7. Vichi JM, Costa MF, Oliveira NCM. Repercussões das atividades de educação em saúde frente à detecção precoce do câncer de mama. Rev Rede Cuid Saúde [Internet]. 2016 [acesso em 2017 abr 11];10(3):1-4. Disponível em: http://publicacoes.unigranrio.edu.br/index.php/rcs/article/view/2823/2063.

8. Andrade IA, Santos IR, Camargo DBB, Linhares TT, Araújo DF. BRCA1, BRCA2, Família ALDH e ADH: Genes relacionados ao etilismo e ao câncer de mama feminino. Rev Pat Tocantins [Internet]. 2017 [acesso em 2017 abr 11];4(1):39-64. Disponível em: https://sistemas.uft.edu.br/periodicos/index.php/patologia/article/view/2426.

9. Malta DC, Jorge AO. Análise de tendência de citologia oncótica e mamografia das capitais brasileiras. Ciênc Cult [Internet]. 2014 [acesso em 2017 abr 11];66(1):25-9. Disponível em: http://dx.doi.org/10.21800/S0009-67252014000100012. 


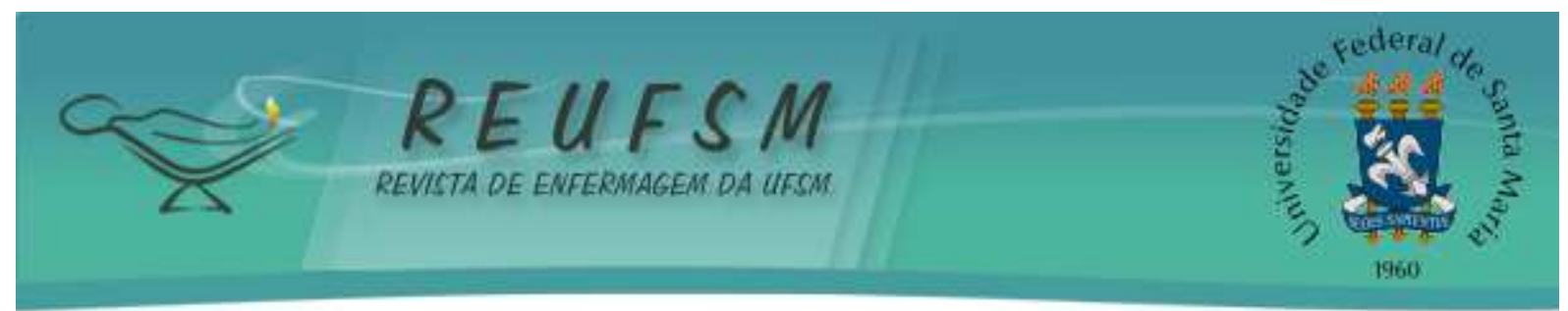

10. Viegas AC, Schwartz E, Zillmer JGV, Muniz RM, Santos BP, Borba DLL, et al. Perfil das mulheres em tratamento quimioterápico em um município no Sul do Brasil. Rev enferm UFSM [Internet]. 2014 abr-jun [acesso 2017 jun 23];4(2):389-400. Disponível em: http://periodicos.ufsm.br/reufsm/article/view/10530.

11. Ossege A, Garrafa V. Bioética e mapeamento genético na seleção de trabalhadores. Rev Saúde Deb [Internet]. 2015 jan-mar [acesso 2017 jun 23];39(104):226-38. Disponível em: www.scielo.br/pdf/sdeb/v39n104/0103-1104-sdeb-39-104-00226.pdf.

12. Jurberg C, Machado GOC, Rego TM, Souto HM. Álcool e câncer: análise da percepção de uma amostra da população por meio da ferramenta Survey Monkey®. Rev Eletron Comum Inf Inov Saúde [Internet]. 2015 jul-set [acesso em 2017 Abr 12];9(3):1-13. Disponível em: http://www.reciis.icict.fiocruz.br/index.php/reciis/article/view/982.

13. Gonçalves JG, Siqueira ASE, Rocha IGA, Lima EFF, Alves LS, Silva BO, et al. Evolução histórica das políticas para o controle do câncer de mama no Brasil. Diversitates Inter J [Internet]. 2016 jul [acesso em 2016 abr 12];8(1):1-23. Disponível em: http://www.diversitates.uff.br/index.php/1diversitates-uff1/article/view/109/83.

14. Brasil. Ministério da Saúde. Secretaria de Atenção à Saúde. Departamento de Atenção Básica. Controle dos cânceres do colo do útero e da mama. $2^{\mathrm{a}}$ ed. Brasília: Editora do Ministério da Saúde; 2013.124 p.

15. Gomes LMX, Alves MC, Santos TB, Andrade-Barbosa TL, Leite MTS. Conhecimento e prática do autoexame das mamas por acadêmicas de enfermagem. Rev Cuba Enferm [Internet]. 2012 [acesso em 2014 mar 22];28(4):465-73. Disponível em: http://scielo.sld.cu/scielo.php?pid=S0864-03192012000400003\&script=sci_arttext.

Data de submissão: 07/07/2017

Data de aceite: 03/08/2018

Autor correspondente: Janaína Pereira Jales Rocha

E-mail: janainajales@hotmail.com

Endereço: Silva Amaro, 916, Abolição 4

CEP: 59614180 